\title{
INVENTÁRIO DA LIBRAS NO TOCANTINS: CONSTITUIÇÃO E COLETA DE DADOS
}

Inventory of libras in Tocantins: constitution and data gathering

Inventario de libras en Tocantins: constitución y recolección de datos

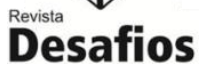

Artigo Original Original Article Artículo Original

Carlos Roberto Ludwig ${ }^{* 1}$, Renato Jefferson Bezerra Leão ${ }^{2}$, Roselba Gomes de Miranda ${ }^{2}$, Bruno Gonçalves Carneiro ${ }^{3}$, Maria Inez de Souza Maia², José Ishac Brandão El Khouri², Cristiano Pimentel $\mathrm{Cruz}^{2}$, Felipe de Almeida Coura ${ }^{4}$, Rodrigo Augusto Ferreira ${ }^{2}$, Alanna Alencar de Araújo Cruz ${ }^{2}$, Gésica Suellen Sobrinho Costa ${ }^{5}$, Gabriela Otaviani Barbosa ${ }^{5}$, Cleysson Wender Fernandes Pires ${ }^{6}$, Lucas Fagundes ${ }^{6}$

${ }^{1}$ Professor do Programa de Pós-Graduação em Letras e do Curso de Letras da UFT, Porto Nacional, Brasil.

${ }^{2}$ Mestrando pelo Programa de Pós-Graduação em Letras e professor do Curso de Letras: Libras da UFT, Porto Nacional, Brasil.

${ }^{3}$ Doutorando pelo Programa de Pós-Graduação em Letras e Linguística da UFG e professor do Curso de Letras: Libras da UFT, Porto Nacional, Brasil.

${ }^{4}$ Doutorando pelo Programa de Pós-Graduação em Linguística da UFMG e professor do Curso de Letras: Libras da UFT, Porto Nacional, Brasil.

${ }^{5}$ Mestre pelo Programa de Pós-Graduação em Linguística da UFSC e professora do Curso de Letras: Libras da UFT, Porto Nacional, Brasil.

${ }^{6}$ Graduando do Curso de Letras: Libras da UFT, Porto Nacional, Brasil.

*Correspondência: Programa de Pós-Graduação em Letras, Universidade Federal do Tocantins, Campus de Porto Nacional, Rua 03, Quadra 17, Lote 11, s/n ${ }^{\circ}$, Porto Nacional, Tocantins, Brasil. CEP:77.000-00. e-mail carlosletras@mail.uft.edu.br

Artigo recebido em 26/08/2018 aprovado em 12/07/2019 publicado em 23/03/2020.

\section{RESUMO}

Este artigo discute a proposta de documentação da libras que será desenvolvida no âmbito do projeto Inventário da Língua Brasileira de Sinais da Região Metropolitana de Palmas - Tocantins. Inicialmente pontuamos algumas questões sobre a libras e a documentação das línguas de sinais. Em seguida, focamos algumas questões contextuais que têm impacto significativo na constituição de um corpus da libras no estado do Tocantins. Por fim, apresentamos a equipe de trabalho e a metodologia de coleta, transcrição e análise dos dados do Inventário da Língua Brasileira de Sinais da Região de Palmas - Tocantins.

Palavras-chave: Documentação da libras. Inventário da libras. Metodologia de coleta e transcrição de dados da libras.

\section{ABSTRACT}

This essay discusses the proposal of documentation of Brazilian Sign Language (Libras) which will be developed at the project Inventory of Brazilian Sign Language at the Metropolitan Region of Palmas - Tocantins. We first point out some issues on Libras and Sign Language documentation. Then, we turn to some contextual issues which have significant impact on the constitution of a corpus of libras at Tocantins State. Finally, we present the project team and the methodology of data gathering, transcription and analysis of the inventory of Brazilian Sign Language of the Metropolitan Region of Palmas - Tocantins.

Keywords: Documentation of libras. Inventory of libras at Tocantins. Methodology of data gathering and transcription of libras 


\section{RESUMEN}

Este artículo discute la propuesta de documentación de la libras que se desarrollará en el marco del proyecto Inventario de la Lengua Brasileña de Señas de la Región Metropolitana de Palmas - Tocantins. Primero puntuamos algunas cuestiones sobre la libras y la documentación de las lenguas de señas. A continuación, enfocamos algunas cuestiones contextuales que tienen un impacto significativo en la constitución de un corpus de la libras en el estado de Tocantins. Por último, presentamos el equipo de trabajo y la metodología de recolección, transcripción y análisis de los datos del inventario de la Lengua de Señas Brasileña de la Región de Palmas Tocantins.

Descriptores: Documentación de las libras. Inventario de libras. Metodología de recolección y transcripción de datos de libras.

\section{INTRODUÇÃO}

Este artigo discute a proposta de documentação da libras que será desenvolvida no Inventário da Língua Brasileira de Sinais da Região Metropolitana de Palmas - Tocantins. A pesquisa será desenvolvida pelo Curso de Letras: Libras em parceria com o Programa de Pós-Graduação em Letras, da Universidade Federal do Tocantins (UFT), Campus de Porto Nacional. O projeto do Inventário da Libras da Região Metropolitana de Palmas - TO está vinculado a um projeto maior - Inventário Nacional da Língua Brasileira de Sinais, do IPHAN, coordenado pela Profa. Dra. Ronice Müller de Quadros, da Universidade Federal de Santa Catarina (UFSC). Por isso, seus objetivos são, em parte, os mesmos utilizados pelo projeto matriz, devidamente adaptados à realidade do estado do Tocantins. O Inventário da Libras da Região Metropolitana de Palmas - TO tem por finalidade criar um corpus da libras representativo do estado do Tocantins. Por isso, trata-se de uma replicação do Inventário Nacional da Língua Brasileira de Sinais neste estado, conforme prevê o projeto matriz, com sede na UFSC. Por esta razão, serão adotados os mesmos procedimentos metodológicos daquele projeto, a fim de se comparar os dados coletados no Tocantins com os dados de corpora de outros estados brasileiros. Apresentaremos algumas considerações sobre a libras e a documentação das línguas de sinais. Em seguida, apresentaremos a constituição e a metodologia de coleta, transcrição e análise dos dados.

\section{Aspectos teóricos sobre a libras e a documentação de línguas de sinais}

A libras é uma língua de modalidade gestualvisual-espacial utilizada pela comunidade surda dos centros urbanos brasileiros. Apesar de ser reconhecida pela Lei $N^{\circ} 10.436 / 2002$, não significa que esteja longe de se tornar uma língua em risco, conforme já discutido por Leite e Quadros (2014). A libras e outras línguas sinalizadas, consideradas línguas de sinais nacionais, podem ser classificadas como línguas em risco esquecidas. Segundo Leite e Quadros (2014),

no caso das línguas de sinais nacionais, o seu caráter de risco está menos no nível de proximidade da extinção do que no fato de a grande maioria das pessoas que delas dependem para o seu desenvolvimento linguístico, cognitivo, social e cultural só poderem ter acesso a ela de maneira tardia. Como agravante, esse contato tardio frequentemente se dá não com uma língua plenamente desenvolvida e gramaticalizada, mas com uma versão pidginizada da língua, utilizada por usuários que a dominam precariamente como uma segunda língua. E completando esse quadro dramático, todo esse processo precário de aquisição ocorre sob a mediação de uma sociedade que carrega fortes estereótipos e falsos conceitos sobre a natureza das línguas de sinais e sobre o estatuto social das pessoas surdas (LEITE e QUADROS, 2014, p. 18). 
O contato das crianças surdas, filhas de pais ouvintes, com a libras e suas variantes acontece de maneira tardia e, na maioria das vezes, se dá ao contato com intérpretes e professores que, muitas vezes, não são fluentes e possuem uma relação de segunda língua com a libras. Tudo isso dificulta a aquisição e o aprendizado da língua. Além do mais, e o mais agravante, a criança surda frequentemente é obrigada a recriar a libras a partir de versões pidginizadas, visto que o contato tardio com esses "fragmentados" não provê um insumo linguístico suficiente para a aprendizagem da língua, bem como conviver com os preconceitos de uma sociedade ouvintista que insiste em enxergar deficiência na surdez.

O estatuto de risco das línguas de sinais não se aplica apenas à libras, mas a todas as línguas de sinais do Brasil. Leite e Quadros (2014) argumentam ainda que

tanto línguas de sinais nativas quanto a língua de sinais nacional vivenciam uma situação 'de risco', ainda que sejam riscos de natureza distinta. [...] Surdos e ouvintes usuários de línguas de sinais nativas correm um risco real de ver a sua língua desaparecer, quando confrontados com a existência de uma língua de sinais nacional. Esse risco provém de uma visão de que aquilo que provém dos grandes centros é melhor do que aquilo que provém das pequenas comunidades, um raciocínio similar ao dos povos europeus diante dos "povos selvagens" das Américas, África e Ásia, que marcou a era colonial (LEITE e QUADROS, 2014, p. 19).

Visto que há um risco de algumas línguas sinalizadas serem extintas ou esquecidas num cenário nacional, é essencial a documentação e o desenvolvimento de pesquisas que contribuam para o reconhecimento, preservação e consolidação da libras e suas variantes, bem como de línguas de sinais locais.
Segundo Quadros e Silva (2017), com base nos estudos de Nonaka (2004), há uma distinção das línguas de sinais em nacionais, nativas e originais, as quais podem ser caracterizadas da seguinte forma:

as línguas de sinais nacionais desfrutam de algum reconhecimento e/ou políticas linguísticas que as colocam como língua oficial da comunidade surda de seus respectivos países; as línguas de sinais nativas são faladas em pequenas comunidades pouco ou nada urbanizadas, em geral distantes dos grandes centros, que apresentam grande incidência de surdez; e as línguas de sinais originais, que também eram faladas por pequenas comunidades de surdos previamente à instituição de uma língua de sinais nacional no país (QUADROS e SILVA, 2017, p. 143).

De acordo com Leite e Quadros (2014), não há evidências documentais sobre línguas de sinais originais do Brasil, previamente à emergência da libras no INES a partir do século XIX ${ }^{1}$. Dentre as línguas de sinais nativas brasileiras, os autores mencionam a língua de sinais kaapor brasileira, no Maranhão, e a cena, no Piauí. A libras se enquadra como exemplo de uma língua de sinais nacional.

No caso da libras, uma língua nacional, apesar do reconhecimento oficial, ainda é uma língua em situação de risco, que carece de documentação (LEITE e QUADROS, 2014). Nas palavras de

\footnotetext{
${ }^{1}$ O Instituto Nacional de Educação de Surdos foi fundado em 1857 por Dom Pedro II, no Rio de Janeiro e está hoje em atividade como a principal instituição para surdos no Brasil. Por muitos anos, o INES funcionou como escola estilo internato. De acordo com Zeshan (2013), as línguas de sinais surgem sempre que surdos se reúnem em número suficiente para formar uma comunidade linguística. A história de muitas línguas de sinais está relacionada, mas não restrita, à implementação de políticas educacionais, com a criação de escolas estilo internatos. Isso favoreceu a reunião de surdos que, provavelmente, não teriam se encontrado de outra forma. Mas, segundo a autora, a estandardização de uma língua de sinais pode acontecer de maneira independente, sem qualquer influência de políticas educacionais.
} 
Quadros e Silva (2017, p. 143), “é a documentação que permitirá não apenas às comunidades usuárias dessas línguas, mas a toda população do país, reconhecer o valor e a riqueza de suas particularidades linguísticas e das perspectivas culturais nelas imbuídas". Nesse sentido, a documentação das línguas de sinais contribui significativamente para o reconhecimento e a valorização da língua, bem como da cultura e das identidades surdas. Da mesma forma, outras línguas de sinais nativas e originais do Brasil, utilizadas por comunidades minoritárias, necessitam de documentação sistemática para que saiam da "zona de risco".

As pesquisas linguísticas sobre as línguas de sinais iniciaram de maneira sistemática com o estudo seminal de Stokoe, em 1960. Antes disso, a língua de sinais americana (ASL) não era considerada uma língua natural, mas apenas gestos e mímicas aleatórios. Stokoe (1960) percebeu que a ASL apresentava unidades mínimas distintivas e recombinativas, assim como as línguas faladas. A partir dessa constatação, o linguista norte-americano estabeleceu três parâmetros para ASL: Configuração de Mão (CM), Locação (L) e Movimento (M). Os achados de Stokoe serviram de base para pesquisas de línguas de sinais em outros países. Mais tarde, foram acrescentados também os parâmetros Orientação da Palma (Or) e Expressões Não-Manuais (ENMs) (BATTISON, 1978 apud FERREIRABRITO, 1995).

Após o reconhecimento das línguas de sinais como línguas humanas naturais, vários estudos foram desenvolvidos nos campos de estudo da linguística das línguas de sinais. A partir desses estudos iniciais, outros pesquisadores se debruçaram sobre a análise linguística da libras, em particular Ferreira (1984; 1995), Felipe (1988; 1998), Quadros (1999), Quadros e Karnopp (2004), Xavier (2006; 2014), Leite (2008), Nascimento (2003; 2009), dentre outros. Esses estudos demonstram a riqueza e a complexidade da língua brasileira de sinais, bem como comprovam que a libras apresenta todas as características de uma língua natural, como quaisquer outras línguas humanas.

Apesar desses estudos, ainda há uma carência muito grande de pesquisas sobre as línguas de sinais, sobretudo no Brasil. Embora haja estudos bastante desenvolvidos sobre outras línguas de sinais, bem como haja arcabouços teóricos das línguas sinalizadas com certo avanço, nada garante que uma língua de sinais consiga driblar o estatuto de risco sem a documentação sistemática, consistente e abrangente. Nesse sentido, é premente a necessidade da expansão do Inventário Nacional da Libras em todos os estados brasileiros e no Distrito Federal.

Num contexto de carência de documentação das línguas de sinais, os desafios de pesquisa são muitos, desde a qualidade das filmagens, a captura de detalhes dos fenômenos articulatórios manuais e nãomanuais e do uso produtivo do espaço de sinalização, até problemas de registro, armazenamento e recuperação dos dados coletados. Um pesquisador perde horas investigando determinado sistema que compõe a estrutura gramatical da língua, por exemplo, na falta de um corpus sistematizado da língua de sinais em questão. Para uma análise detalhada de vários aspectos envolvidos na sinalização, é necessária uma descrição minuciosa e sutil do corpo e do espaço em um contexto discursivo, para que o pesquisador consiga apreender todos os detalhes envolvidos na sinalização, os quais contribuem significativamente para a análise precisa e consistente de uma língua de sinais (LEITE, 2008; LEITE e QUADROS, 2014). 
Além disso, conforme menciona Quadros (2016),

a documentação da Libras está diretamente relacionada com as funções difusão das línguas e manutenção das línguas. Estas duas funções estão relacionadas também com a revitalização da Libras, uma vez que essa língua passa a [figurar] em diferentes espaços dentro da sociedade brasileira, a partir dos desdobramentos das ações previstas no Decreto 5.626 (QUADROS, 2016, p. 160).

Nesse sentido, o Inventário da Libras no Tocantins supre essa necessidade premente de identificação, reconhecimento, valorização e documentação da língua brasileira de sinais, em particular as variantes em uso no estado do Tocantins. Além disso, da documentação da libras no Tocantins, análises com dados do corpus da libras serão desenvolvidas, a fim de oportunizar mais estudos linguísticos na área, não só no Tocantins, mas também no cenário nacional. Nesse sentido, estudos das variantes locais, bem como análises comparativas com os dados do inventário de outros estados brasileiros contribuirão qualitativamente e quantitativamente para a compreensão do sistema linguístico da língua brasileira de sinais.

Vale salientar que a sistematização dos procedimentos de documentação das línguas de sinais, tais como os de coleta, registro, armazenamento e recuperação de dados e metadados das línguas de sinais no mundo têm recebido muita atenção nas pesquisas nos últimos anos, como nos estudos de Crasborn, van der Kooij e Mesch (2004); Efthimiou e Fotinea (2007); Hanke (2000); Leeson, Saeed e Byrne-Dunne (2006); Schembri (2008); e Chen-Pichler et. al. (2010). No Brasil, a criação dos Inventário Nacional da Língua Brasileira de Sinais permite a sistematização e a disponibilização de dados em escala bastante satisfatória. Para concretizar a proposta de documentação sistemática e consistente da língua, o Inventário Nacional da Libras será replicado em todos os estados brasileiros, contribuindo para a documentação, valorização e pesquisas da libras e de outras línguas de sinais, próximo ao contexto da língua em uso.

\section{Situando o Inventário da língua brasileira de sinais da Região de Palmas - Tocantins}

Apesar de a libras ser legalmente reconhecida no Brasil, ainda há uma escassez muito grande de pesquisas sobre a libras em muitas regiões do país. $\mathrm{O}$ estado do Tocantins se enquadra nesse contexto em que a libras ainda carece de pesquisas.

No entanto, Carneiro e Nunes (2014) traçam uma trajetória de conquistas da comunidade surda tocantinense, o que tem refletido no empoderamento dos surdos no Tocantins e no prestígio da libras. Segundo os autores, a trajetória de lutas e negociações do movimento surdo nacional que se intensificou nos últimos anos, a favor de uma educação bilíngue, refletem em todo o território brasileiro, ainda que de modo diverso. Desta forma, é possível vermos também a articulação de comunidades surdas a nível regional, em prol e em consequência dessas conquistas, a organizar-se a favor de suas comunidades de fala e do usufruto desses ganhos. É o que se observa no estado do Tocantins.

Além disso, algumas ações do poder público estão potencializando esse cenário. Com a Lei $\mathrm{N}^{\circ}$ 10.436, a Lei da Libras, e o Decreto $N^{\circ} 5.626$, foram criados cursos de Letras: Libras em todo o Brasil. Nesse sentido, algumas mudanças em relação à perspectiva surda na produção de conhecimento, principalmente com a criação do Curso de Letras: Libras da UFT, no Campus de Porto Nacional, bem como implantação de uma seleção do Programa de 
Pós-Graduação em Letras específica para a área de libras e formação de surdos.

O Curso de Letras: Libras, habilitação Licenciatura, iniciou suas atividades no primeiro semestre letivo do ano de 2015, no Campus de Porto Nacional. O Curso oferta trinta (30) vagas e funciona em modalidade presencial no turno matutino. Prevêse a implantação da habilitação Bacharelado em Tradução e Interpretação em Língua Brasileira de Sinais, que também ofertará trinta (30) vagas. Para garantir a qualidade e o pleno funcionamento de ambas as habilitações do Curso de Letras: Libras, o curso desenvolve atividade de ensino, pesquisa e extensão. Atualmente, são 9 professores surdos e 8 professores ouvintes no Curso de Letras: Libras. Ao todo, a UFT possui 13 docentes surdos efetivos, sendo que 9 atuam no curso de Letras: Libras, em Porto Nacional, e 4 atuam nos campus da UFT em Araguaína, Arraias, Miracema e Tocantinópolis, em atividades de ensino, pesquisa e extensão.

Assim também, o Programa de PósGraduação em Letras (Mestrado em Letras) do Campus de Porto Nacional foi criado em 2015. Em 2017, o Mestrado em Letras adotou políticas de ações afirmativas propostas pelo MEC, voltadas especificamente para a comunidade surda para desenvolver pesquisas em libras. A seleção engloba temas e bibliografia específica sobre a libras, assim como prova teórica e entrevista realizadas em língua brasileira de sinais. Além disso, a prova de língua estrangeira pode ser realizada em português como segunda língua. Essa é uma tendência de alguns concursos e processos seletivos, conforme já discutido por Carneiro (2018). A partir dessa proposta de seleção específica, foram selecionados 6 mestrandos surdos que pesquisam sobre a libras e a educação de surdos. Em 2018, foram selecionados mais 4 mestrandos surdos, totalizando 10 surdos na pós-graduação. Eles desenvolvem pesquisas voltadas para a descrição e análise linguística da libras, estudos do léxico da libras, ensino e aprendizagem da libras, política linguística e linguística cognitiva. Assim também, a partir do ingresso de mestrandos surdos, 2 docentes do programa iniciaram pesquisas sobre a libras com o intuito de aprofundar questões teóricas, metodológicas e de documentação sobre a língua brasileira de sinais.

Com a criação do curso de Letras: Libras e a implantação de uma seleção específica para surdos no Mestrado em Letras da UFT, algumas pesquisas já são desenvolvidas nas áreas de libras e de educação de surdos no Tocantins, tais como: estudos sobre verbos de indicação em libras (CARNEIRO, CRUZ e KHOURI, 2017); estudos do léxico e gramática da libras (CARNEIRO, 2015, 2016a, 2016b); epistemologias surdas (CARNEIRO e LUDWIG, 2018); português como L2 para surdos (CARNEIRO, 2018); políticas linguísticas e educacionais em escrita de sinais (LEÃO e CARNEIRO, 2019); sinalários de termos científicos em libras na educação básica (PAZ, MIRANDA e CARNEIRO, 2016); história sobre a educação de surdos (MAIA, 2017), letramento crítico e educação de surdos (COURA, 2016; 2017). Embora existam algumas pesquisas sobre a libras sendo desenvolvidas no Tocantins, há uma carência no estado de documentação da libras para fins de pesquisa e produção de material didático que enfoquem as variações linguísticas da libras utilizadas por surdos no estado. Nesse sentido, o Inventário da Libras da Região de Palmas visa contribuir para suprir essas lacunas, desenvolvendo pesquisas sobre a libras, utilizando-se das variantes linguísticas locais.

Vale ressaltar que, no contexto regional, o estado do Tocantins possui uma posição geográfica favorável, o que facilita e contribui 
significativamente para a formação de recursos humanos altamente qualificado, que atenda não somente o estado do Tocantins, mas também os estados da região norte e os estados limítrofes da região nordeste e centro-oeste. Como prova disso, o Curso de Letras: Libras e o Programa de PósGraduação em Letras têm recebido discentes do Maranhão, Pará, Amapá, Piauí, Ceará, Bahia, Goiás e Distrito Federal, incluindo discentes surdos. Além do mais, a Universidade Federal do Tocantins é a terceira universidade do norte do Brasil em termos de produção científica. Nesse cenário, o Inventário da Libras da Região de Palmas servirá de referência para a criação de outros projetos de documentação da libras e de outras línguas de sinais nos estados limítrofes do Tocantins, bem como de toda a região norte do país.

Assim, o projeto Inventário da Libras da Região de Palmas - Tocantins objetiva iniciar a composição do corpus da libras, por meio de um inventário da língua brasileira de sinais usada na Região Metropolitana de Palmas, Tocantins. O inventário da libras visa identificar, reconhecer, valorizar e promover a libras e suas variantes (QUADROS e LUDWIG, 2018). O inventário se insere no contexto do Inventário Nacional da Diversidade Linguística, do Departamento do Patrimônio Imaterial/Iphan, Ministério da Cultura, que tem como objetivo criar inventários de todas as línguas em uso no Brasil. Dessa forma, o Inventário da Libras do Estado do Tocantins, região metropolitana de Palmas, servirá de referência para o inventário de Libras juntamente com os demais estados.

O Inventário da Libras da Região de Palmas possibilita a promoção de impactos acadêmico, científico e social. Do ponto de vista acadêmico, o projeto se configura como uma proposta que envolverá alunos de graduação do Curso Letras: Libras, bem como do Mestrado em Letras. Nesse sentido, haverá o desenvolvimento de pesquisas que integram alunos de graduação e pós-graduação, o que possibilitará a formação de profissionais com perfil de pesquisadores na área da língua brasileira de sinais. Na esfera científica, serão desenvolvidos processos e produtos relativos à documentação, descrição e análise da língua brasileira de sinais, o que aprofundará as questões teóricas e metodológicas da pesquisa sobre a libras. Nesse sentido, o inventário é um instrumento que potencializa o desenvolvimento de epistemologias surdas que ocuparão cada vez mais o espaço de pesquisa na sociedade brasileira, suprindo uma necessidade histórica da comunidade surda brasileira (CARNEIRO e LUDWIG, 2018). Em relação ao impacto social, enfatizamos a valorização da língua, da cultura e das identidades da comunidade surda local e regional.

Nesse sentido, o projeto Inventário da Língua Brasileira de Sinais da Região de Palmas - Tocantins oportunizará o impacto social, intelectual e cultural da comunidade surda do estado do Tocantins, a partir da atuação direta das pessoas surdas na execução do projeto. Assim, o Inventário da libras do Tocantins possibilitará a) o incentivo ao ingresso das pessoas ao curso de Letras: Libras, bem com ao continuação dos estudos na pós-graduação, a fim de promover o desenvolvimento de epistemologias surdas; b) a formação de pesquisadores altamente capacitados, no curso de Letras: Libras e no Programa de PósGraduação em Letras da UFT, em parceria com a UFSC, no tocante à descrição e análise da libras e educação de surdos.

\section{Metodologia de coleta dos dados do Inventário da}

\section{Libras no Tocantins}

Considerando que o projeto do Inventário da Libras da Região Metropolitana de Palmas - TO está Revista Desafios - v. 7, n. 1, 2020 
vinculado a um projeto maior - Inventário Nacional da Língua Brasileira de Sinais, da UFSC, seus objetivos serão, em parte, os mesmos utilizados pelo projeto matriz, devidamente adaptados à realidade do estado do Tocantins. O Inventário da Libras da Região de Palmas tem por finalidade criar um corpus da libras representativo do estado do Tocantins e está vinculado ao projeto Inventário Nacional da Língua Brasileira de Sinais, da UFSC, coordenado pela Profa. Dra. Ronice Müller de Quadros, que chamamos de projeto matriz. Por isso, trata-se de uma replicação do Inventário Nacional da Língua Brasileira de Sinais no estado do Tocantins, conforme prevê o projeto matriz, com sede na UFSC. Por esta razão, serão adotados os mesmos procedimentos metodológicos daquele projeto, a fim de se comparar os dados coletados no estado do Tocantins com os dados de corpora de outros estados brasileiros. Dessa forma, a Região Metropolitana Palmas passa a compor o Inventário Nacional da Língua Brasileira de Sinais, juntamente com as demais capitais que hoje fazem parte do projeto. Atualmente, integram o Inventário Nacional da Língua Brasileira de Sinais os estados de Alagoas, Ceará, Rio de Janeiro, Santa Catarina e Tocantins.

Com o propósito de utilizar os mesmos critérios de coleta de dados do Projeto Inventário Nacional da Língua Brasileira de Sinais da UFSC, o presente projeto coletará apenas os dados da Região Metropolitana de Palmas. Por esse motivo, trata-se de um "corpus representativo", visto que não teremos representação da língua sinalizada da comunidade surda de todas as regiões do Tocantins.

Apesar de a primeira fase do projeto envolver apenas a região metropolitana de
Palmas, na segunda fase do projeto pretendemos fazer a coleta dos dados de outras regiões do estado do Tocantins. Para tanto, serão redefinidos o número de informantes, a metodologia de coleta e a escolha dos informantes, em conjunto com o projeto matriz, Inventário Nacional da Língua Brasileira de Sinais, da UFSC, coordenado pela Profa. Dra. Ronice Müller de Quadros.

A Região Metropolitana de Palmas (TO) é regulamentada pela Lei Estadual $\mathrm{N}^{\mathrm{o}} 2.824$, de 30 de dezembro de 2013. A região metropolitana de Palmas é composta por 16 municípios, a saber: Palmas, Aparecida do Rio Negro, Barrolândia, Brejinho de Nazaré, Fátima, Ipueiras, Lajeado, Miracema do Tocantins, Miranorte, Monte do Carmo, Oliveira de Fátima, Paraíso do Tocantins, Porto Nacional, Pugmil, Silvanópolis e Tocantínia (Figura 1).

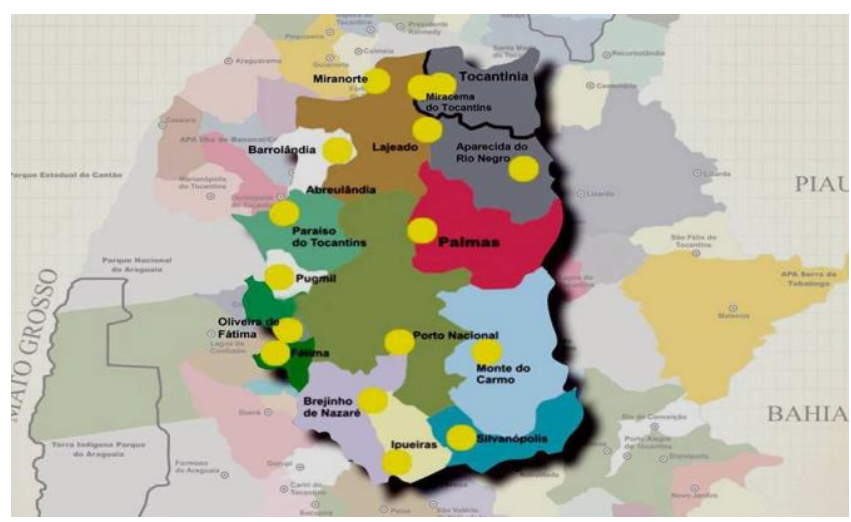

Figura 1 - Mapa da Região Metropolitana de Palmas - Tocantins

Fonte:

https://secom.to.gov.br/noticia/174518/

No escopo do presente projeto, a pesquisa vai iniciar a constituição do inventário da libras com um corpus que representa a língua brasileira de sinais em uso na região metropolitana de Palmas, estado do Tocantins. A constituição do corpus de libras em Revista Desafios - v. 7, n. 1, 2020 
Palmas vai envolver uma equipe de pesquisadores do Curso de Libras: Libras e do Programa de PósGraduação em Letras da Universidade Federal do Tocantins, com o apoio da coordenadora do Inventário Nacional da Língua Brasileira de Sinais, Profa. Dra. Ronice Quadros, da Universidade Federal de Santa Catarina. A definição dos instrumentos e do detalhamento do formato do corpus da libras foi definida nesta primeira etapa, em que já são realizadas as primeiras coletas de dados do Inventário de Libras com a perspectiva de constituição de um projeto nacional. $\mathrm{O}$ projeto iniciou, portanto, com o estado de Santa Catarina e, neste segundo momento, essa proposta está sendo replicada nos demais estados, dentre eles o Tocantins, contando com pesquisadores e colaboradores locais.

\section{A escolha dos informantes e questões éticas da pesquisa}

Como informantes, serão selecionados membros da comunidade surda da região metropolitana da Palmas - Tocantins, os quais devem atender os seguintes critérios:

\footnotetext{
i) ser nato do estado, ou residir no estado do Tocantins por pelo menos 10 anos; ii) ter adquirido a libras em idade pré-escolar (até 7 anos de idade), ou no mínimo por mais de 7 anos (tempo de exposição à língua), ou com proficiência notória na comunidade; iii) a dupla deverá ser formada por pessoas íntimas entre si (amigos ou parentes), preferencialmente do mesmo gênero e faixa etária (LUDWIG e QUADROS, 2018, p. 18).
}

Além do mais, é importante que, dentre as 18 duplas que serão entrevistadas, o pesquisador local e sua assistente busquem selecionar duplas com perfis variados. Deverão levar em consideração os seguintes critérios: o conjunto de 36 informantes deve conter surdos que façam parte de 3 grupos distintos, assim distribuídos: Grupo 1 (G1) deve ser composto por surdos jovens (até 29 anos); Grupo 2 (G2), por surdos de meia idade (entre 30 e 49 anos); e o Grupo 3 (G3) deve ser representado por surdos com idade avançada (a partir de 50 anos) (LUDWIG e QUADROS, 2018). Dentre os 3 grupos de surdos, cada grupo será composto de 12 surdos, formando 6 duplas, sendo 3 duplas de mulheres e 3 duplas de homens. Todos os surdos deverão ser maiores de 18 anos. Preferencialmente, os surdos deverão ter "diferentes graus de escolarização (ensino fundamental, ensino médio e ensino superior completo)" (LUDWIG e QUADROS, 2018, p. 18).

Selecionaremos 36 surdos da região metropolitana de Palmas como informantes. Esses 36 surdos serão entrevistados em duplas, constituindo assim 18 entrevistas. Estima-se que a coleta de dados com cada dupla tenha aproximadamente 2 horas, o que totaliza 72 horas de vídeo (QUADROS, 2017).

Por fim, só serão aceitos como informantes no Corpus da Libras da Região de Palmas os surdos maiores de 18 anos e que aceitarem, sem quaisquer restrições, "todas as condições de uso e distribuição de suas imagens, tal como será definido no Termo de Consentimento para Participação na Pesquisa" (LUDWIG e QUADROS, 2018, p. 18). Além disso, o projeto já possui a aprovação do Comitê de Ética da UFSC, por meio de uma emenda do projeto matriz, o Inventário Nacional da Libras.

\section{Equipe de pesquisadores do Inventário da Libras no Tocantins}

A sede do projeto será no Curso de Letras: Libras, da Universidade Federal do Tocantins, na cidade de Porto Nacional. A escolha da cidade de Porto Nacional para a realização da coleta, armazenamento e transcrição dos dados se deve ao fato de o Curso de Letras: Libras da UFT ter sua sede na cidade de Porto Nacional, situada a $64 \mathrm{~km}$ da capital Palmas - TO. O curso de Letras: Libras possui 
9 professores surdos efetivos, os quais atuarão diretamente no projeto Inventário da língua brasileira de sinais da Região de Palmas - Tocantins.

Assim, temos maior facilidade de articulação com pesquisadores colaboradores no projeto dentro desta etapa inicial de montagem do corpus. Apesar de restringirmos a coleta de dados à região metropolitana de Palmas neste primeiro momento, temos ciência de que se faz necessário resguardar as variações que representam cada uma das regiões do estado do Tocantins com a continuidade do projeto.

A equipe é formada por um professor pesquisador que será o coordenador local da constituição do corpus do Tocantins. No caso específico da presente etapa, além do coordenador, o projeto conta com bolsas de Iniciação Científica (IC) e de mestrado para contribuir com o projeto. Além disso, dois professores doutorandos fazem parte do Corpus da Libras.

A seleção dos participantes, o primeiro contato de reconhecimento dos informantes e a coleta de dados, será feita por um pesquisador surdo local mais uma assistente. A princípio, o projeto prevê que o pesquisador surdo local deve ser:

i) nato da Região Metropolitana de Palmas, ou residir e conviver com a comunidade surda local por no mínimo 10 anos; ii) pessoa extrovertida e articulada, de preferência com experiência acadêmica em nível de graduação ou pósgraduação; iii) pessoa com conhecimento tecnológico básico para as finalidades do projeto e com facilidade de acesso diário a computador e internet (LUDWIG e QUADROS, 2018, p. 18).

Assim, após pesquisa e discussão com o grupo de pesquisadores do Corpus da Libras do Tocantins, escolhemos um dos pesquisadores do Corpus: Renato Jefferson Bezerra Leão. Ele tem 30 anos, é natural de Petrolina - PE, professor universitário de libras e escrita de sinais do Curso de Letras: Libras, da UFT/Campus de Porto Nacional. Ele atende os requisitos propostos no projeto inicial em sua totalidade: i) ele reside em Palmas e convive com a comunidade surda local por 10 anos, conforme prevê o projeto; ii) é uma pessoa extrovertida e articulada, tem experiência acadêmica em nível de graduação ou pós-graduação. Ele é professor do Curso de Letras: Libras desde 2015 e mestrando em Letras desde agosto de 2017; iii) tem conhecimento tecnológico básico para as atividades do projeto, bem como tem acesso diário a computador e internet com muita facilidade. Além disso, trata-se de um pesquisador solícito, com habilidades de gestão, bem como possui notável articulação política na comunidade surda em âmbito estadual, regional e nacional. Tendo em vista a necessidade de um pesquisador local para realizar as entrevistas e a coleta de dados com perfil acadêmico, extrovertido e articulado, o perfil do pesquisador selecionado se enquadra perfeitamente na proposta do projeto.

Como assistente de identificação dos participantes e das filmagens, foi selecionada Roselba Gomes de Miranda. Ela tem 48 anos, é natural de Balsas - MA, professora universitária de libras do Curso de Letras: Libras da UFT/Campus de Porto Nacional. Ela também atende os requisitos propostos no projeto inicial em quase sua totalidade: i) convive com a comunidade surda local conforme prevê o projeto; ii) é uma pessoa extrovertida e articulada, tem experiência acadêmica em nível de graduação ou pós-graduação. Ela foi professora de libras em Tocantinópolis (UFT), em 2013 a 2014, em Araguaína (UFT), em 2015 a 2017, e atualmente é professora do Curso de Letras: Libras e mestranda em Letras desde agosto de 2017; iii) tem conhecimento tecnológico básico para as atividades do projeto, bem como tem acesso diário a computador e internet com Revista Desafios - v. 7, n. 1, 2020 
muita facilidade. Além disso, possui notável articulação política na comunidade surda em âmbito estadual, regional e nacional. Tendo em vista a necessidade de um pesquisador local para realizar as entrevistas e a coleta de dados com perfil acadêmico, extrovertido e articulado, o perfil da pesquisadora selecionada também se enquadra perfeitamente na proposta do projeto.

O inventário da libras da região de Palmas está iniciando a coleta dos dados. Para tanto, 7 membros da equipe do projeto, ou seja, o coordenador, 5 docentes do Curso de Letras: Libras e um bolsista de iniciação científica do $\mathrm{CNPq}$ realizaram a formação do Inventário Nacional da Libras, na Universidade Federal de Santa Catarina, em Florianópolis, nos dias 11, 12 e 13 de junho de 2018. A equipe do Inventário da Libras da Região de Palmas realizou o treinamento juntamente com as equipes do Inventário Nacional da Libras dos estados do Ceará (com pesquisadores da UFC), de Alagoas (com a equipe da UFAL), do Rio de Janeiro (com pesquisadores do INES) e de Santa Catarina (com a equipe da UFSC). Durante a formação, a equipe aprimorou conhecimentos sobre coleta, transcrição, armazenamento e validação dos dados. Além disso, foi um momento de trocas de experiências com os pesquisadores dos inventários dos outros estados.

Vale ressaltar que os membros da equipe, exceto o bolsista de IC, já tinham conhecimentos de documentação da libras. A equipe adquiriu tais conhecimentos durante a disciplina de Documentação da Libras, ministrada pela Profa. Dra. Ronice Müller de Quadros, nos dias 27 a 30 de novembro de 2017, no Mestrado em Letras do Campus de Porto Nacional. Naquele momento, também foi firmada a parceria entre a UFSC e a UFT para a implantação do Inventário da Libras no Estado do Tocantins.
Neste momento, a equipe do Inventário da Libras da Região de Palmas realiza a replicação do treinamento recebido na UFSC com os outros membros do projeto no Curso de Letras: Libras na UFT. Além disso, está sendo realizada a adaptação dos instrumentos de coleta dos dados recebidos no treinamento na UFSC, como também está sendo realizada a filmagem do TCLE em Libras e a montagem do estúdio de filmagens.

O projeto está estruturado com base na seguinte logística: a coordenação geral do projeto é de responsabilidade do Professor Dr. Carlos Roberto Ludwig e os pesquisadores responsáveis são a Profa. Dra. Ronice Müller de Quadros (UFSC) e Carlos Roberto Ludwig (UFT). Aos pesquisadores que realizaram o treinamento na UFSC, foram atribuídas as seguintes funções, nas quais eles coordenam pequenas equipes de trabalho.

\begin{tabular}{|l|l|}
\hline \multicolumn{1}{|c|}{ Função } & \multicolumn{1}{c|}{ Responsáveis da equipe } \\
\hline $\begin{array}{l}\text { Identificação dos } \\
\text { informantes, filmagens e } \\
\text { coleta dos dados }\end{array}$ & $\begin{array}{l}\text { Renato Leão } \\
\text { Roselba Miranda }\end{array}$ \\
\hline $\begin{array}{l}\text { Responsável pela equipe } \\
\text { de Transcrição }\end{array}$ & José Ishac Brandão Khouri \\
\hline $\begin{array}{l}\text { Responsáveis pela } \\
\text { equipe de Tradução }\end{array}$ & $\begin{array}{l}\text { Bruno Carneiro } \\
\text { Felipe Coura }\end{array}$ \\
\hline $\begin{array}{l}\text { Responsável pelo } \\
\text { armazenamento dos } \\
\text { dados }\end{array}$ & Maria Inez Maia \\
\hline Validação dos dados & $\begin{array}{l}\text { Bruno Carneiro } \\
\text { José Ishac Brandão Khouri } \\
\text { Renato Leão } \\
\text { Carlos Ludwig }\end{array}$ \\
\hline
\end{tabular}

Quadro 1 - Responsáveis das Equipes de Trabalho do Inventário da Libras de Palmas - TO Fonte: Elaborado pelos autores do artigo.

A equipe de transcrição dos dados é a maior equipe de trabalho e é a equipe que terá o trabalho 
mais volumoso no inventário. Portanto, necessita de mais pesquisadores envolvidos; será coordenada pelo Professor José Ishac Brandão El Khouri, do Curso de Letras: Libras, com o apoio e supervisão do coordenador do projeto. Fazem parte da equipe de transcrição os seguintes docentes e bolsistas do curso de Letras: Libras: Alanna Alencar de Araújo Cruz, Cristiano Pimentel Cruz, Gabriela Otaviani Barbosa, Gesica Suellen Sobrinho Costa, Rodrigo Augusto Ferreira, Cleysson Wender Fernandes Pires (Bolsista de IC), Amoriana Borges de Araújo (discente voluntária), Paulo César Ferreira Guimarães (discente volunário) e Lucas Fagundes (discente voluntário). Todos os membros dessa equipe são surdos e fazem parte da comunidade surda local.

Nesse sentido, vale destacar que apenas três membros da equipe do projeto são ouvintes. Os outros pesquisadores da equipe são surdos e fazem parte da comunidade surda do Tocantins. Nesse sentido, o Inventário da Libras da Região de Palmas TO incentiva fortemente o protagonismo de sujeitos surdos, o que dá visibilidade e empoderamento à comunidade surda, sua cultura e identidades, bem como possibilita o desenvolvimento de epistemologias surdas.

\section{Coleta, transcrição e validação dos dados}

A coleta dos dados será realizada por meio de filmagens em um estúdio no Curso de Letras: Libras, da UFT/Campus de Porto Nacional. O estúdio de filmagens deverá ser um espaço em que os surdos informantes se sintam à vontade. A equipe de coleta envolverá o pesquisador local surdo, mais uma assistente de filmagens. Haverá um técnico que apoiará a equipe de filmagem, mas só será chamado quando houver necessidade. Além disso, ele não poderá estar presente no estúdio durante as filmagens, para não haver interferências na coleta dos dados.
Conforme já pontuado por Quadros (2016) e Ludwig e Quadros (2018), o estúdio de filmagens conta com 4 filmadoras com o objetivo de captar a sinalização dos informantes em diferentes tomadas. A disposição das câmeras se apresenta da seguinte forma: uma câmera será posicionada na frente dos dois informantes, para captar uma imagem mais panorâmica dos surdos em sua sinalização. Uma câmera será posicionada mais atrás, na lateral do informante 1, para captar a sinalização do informante 2; da mesma forma, uma outra câmera será posicionada mais atrás, na lateral do informante 2 , para captar a sinalização do informante 1. A quarta câmera será instalada no teto do estúdio, de modo que registre a sinalização com vista panorâmica de cima (Figura 2). Essa disposição das câmeras se faz necessária para uma análise sutil e detalhada dos articuladores manuais e não-manuais, conforme pontuado por Leite (2008) e Quadros (2016).
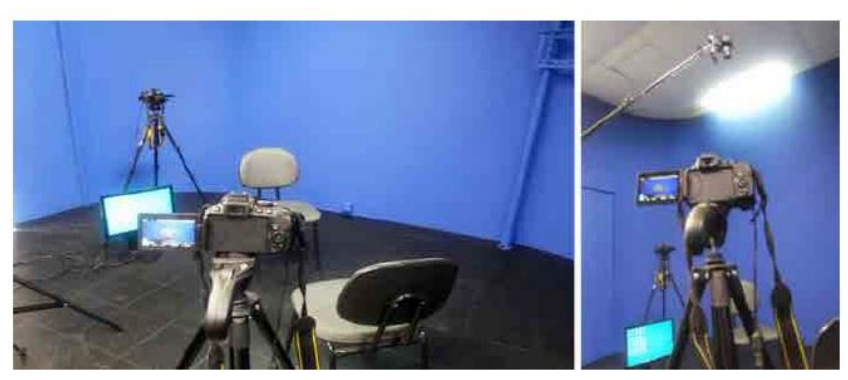

\section{Figura 2 - Posição das Quatro Câmeras no Estúdio de Filmagens}

Fonte: Quadros (2016, p. 167)

Inicialmente, o projeto previa que cada participante teria acesso a um notebook para acesso aos estímulos linguísticos de eliciação em libras. Contudo, após a realização de testes no estúdio do Corpus na UFSC, a fim de atender a comodidade e melhor visibilidade dos estímulos linguísticos, optouse por instalar 2 monitores ligados a 2 notebooks, a partir dos quais os pesquisadores responsáveis pelas filmagens controlarão os estímulos linguísticos de 
cada informante. Vale destacar que cada monitor está posicionado na lateral dos informantes, de modo que o informante 1 só terá acesso aos estímulos projetados no monitor ao lado do informante 2 , ao passo que o informante 2 verá somente os estímulos linguísticos projetados no monitor ao lado do informante 1. Desse modo, cada informante terá acesso a apenas um conjunto de estímulos linguísticos, não podendo ver os dados projetados para o surdo sentado a sua frente (Figura 3).
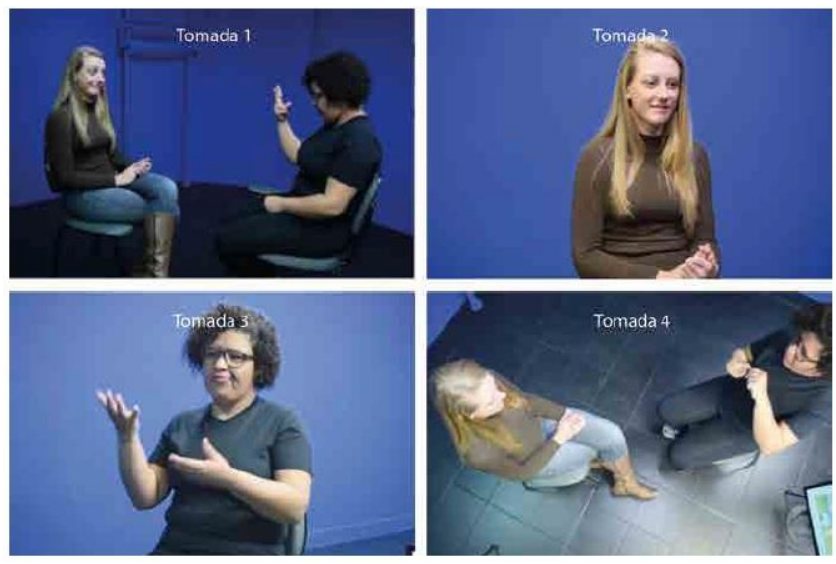

\section{Figura 3 - Tomadas das Entrevistas}

Fonte: Quadros (2016, p. 167)

Os dois pesquisadores surdos têm acesso a dois notebooks, dos quais controlam e manipulam os estímulos linguísticos para registrar as informações das seções de filmagem. As seções com os informantes surdos terão duração aproximada de 2 horas. Apresentarão as seguintes atividades de eliciação e estímulos linguísticos: a) entrevista inicial sobre a vida do informante (20 a 30 minutos); b) eliciação de narrativas, na qual o informante irá recontar 3 narrativas previamente selecionadas: a Pear Story; a Frog: where are you?; e a Canary Row, de Tweety \& Sylvester (30 minutos); c) intervalo de descanso (20 minutos); d) eliciação gramatical e lexical (30 minutos), na qual o informante sinalizará itens lexicais e construções gramaticais por meio de figuras; e) conversão sobre temas pré-determinados (20-30 minutos) f) conversação livre (10 minutos), em que os dois surdos ficarão sozinhos no estúdio para uma conversa livre. (LUDWIG e QUADROS, 2018; QUADROS, 2016).

\section{Armazenamento, transcrição e análise dos dados}

Após a filmagem e coleta dos dados, todos os dados serão armazenados em 4 backups do projeto. Um backup num HD externo de 20 TB localizado no Curso de Letras: Libras; um backup na nuvem, disponível no servidor da UFT; um backup na nuvem, compartilhado no Google docs; e, por fim, um backup num HD externo de $10 \mathrm{~TB}$, que será mantido pelo coordenador do projeto. Essa metodologia de armazenamento dá segurança à manutenção, acesso e recuperação dos dados sempre que necessário. Além disso, as filmagens serão gravadas sempre em 2 pastas de arquivos. Uma pasta com dados brutos e uma segunda pasta com dados editados para serem posteriormente transcritas pela equipe do projeto.

Após o armazenamento, será iniciada a transcrição dos dados. Todos os dados serão transcritos com o ELAN, programa que foi desenvolvido pelo MPI com o objetivo de transcrever, especificamente, dados multimodais, de voz e/ou vídeo (Figura 4). Esse programa está disponível gratuitamente no site http://www.latmpi.eu/tools/. Considerando que transcrição dos dados é bastante complexa e demorada (LEITE, 2008), estima-se que 1 minuto de filmagem leve, em média, 1 hora de trabalho, apenas com as trilhas básica: a) a glosa dos sinais manuais, integrado ao Identificador de Sinais para as mãos direita e esquerda, sempre que necessário; b) tradução para o português (QUADROS e LUDWIG, 2018). A transcrição será realizada a partir de um arquivo modelo utilizados por todos os pesquisadores de 
todos os projetos que compõem o Inventário Nacional da Libras.

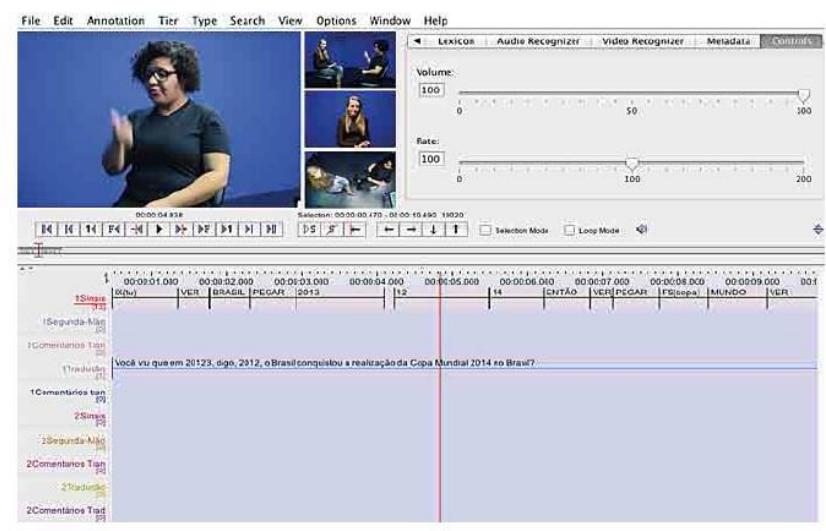

\section{Figura 4 - Tela de um Arquivo do ELAN, com as} quatro tomadas da entrevista

Fonte: Quadros (2016, p. 168)

Além disso, todos os pesquisadores terão acesso permanente às convenções de transcrição do Inventário Nacional da Libras. Periodicamente, as convenções poderão passar por ajustes, conforme as dúvidas e os problemas de transcrição forem surgindo. Para solucionar os problemas de transcrição e tradução, a equipe do Inventário da Libras da Região de Palmas realizará reuniões periódicas para solucionar os problemas e dúvidas das transcrições e traduções.

Assim também, anualmente o Inventário Nacional da Língua Brasileira de Sinais fará cursos de formação presencial em uma das sedes do projeto. A primeira formação foi realizada de 11 a 13 de junho de 2018, na UFSC, em Florianópolis - SC. A segunda formação está programada de 12 a 14 de maio de 2019, na UFAL, em Maceió - AL. Assim também, sempre que necessário, serão realizadas reuniões com as equipes do Inventário Nacional da Libras por videoconferência.

As transcrições realizadas pelos pesquisadores passarão por um processo de validação periódica. Para tanto, os membros mais experientes do projeto farão uma segunda transcrição de amostras de filmagens coletadas no Inventário da Região de Palmas, bem como de outros estados do Inventário Nacional da Libras. Será feita uma análise comparativa para verificar inconsistências e introduzir ajustes sempre que necessário (LUDWIG e QUADROS, 2018; QUADROS, 2016). A validação dos dados visa à manutenção da qualidade das transcrições, o que proporciona mais segurança nas futuras análises dos dados do Inventário da Libras.

\section{Análise dos dados}

As análises dos dados do Inventário da Libras da Região de Palmas - TO serão realizadas em subprojetos dentro do projeto principal. Para tanto, cada pesquisador poderá propor projetos individuais ou em equipe para o desenvolvimento de pesquisas específicas com os dados do inventário da libras. Inicialmente, estão previstas as seguintes pesquisas com os dados do inventário, as quais estão em fase inicial:

\section{- Pesquisa sobre Topônimos da Libras: essa pesquisa} será realizada por Roselba Miranda, orientado pela Profa. Dra. Karylleila Andrade dos Santos. Bruno Carneiro fará parte do projeto como pesquisador. A pesquisa tem o objetivo de identificar e catalogar os topônimos em uso na libras do Tocantins. É uma pesquisa desenvolvida no Programa de PósGraduação em Letras.

- Pesquisa intitulada Variação Fonológica na Libras: Distensão do Polegar: essa pesquisa será realizada por Maria Inez de Souza Maia, com a orientação de Carlos Ludwig. O professor Bruno Carneiro fará parte da equipe de pesquisa. Trata-se de um projeto de dissertação do Mestrado em Letras e tem o objetivo de verificar a acomodação do dedo polegar em sinais manuais em libras.

Revista Desafios - v. 7, n. 1, 2020 
- Pesquisa sobre Número Plural em Libras: essa pesquisa será realizada por Bruno Carneiro. Faz parte de sua pesquisa de doutorado, orientado pela Profa. Dra. Mônica Veloso e tem como objetivo de identificar, mapear e classificar as estratégias de número plural em libras e contrastar com outras línguas de sinais.

- Pesquisa sobre estratégias e sinais de Posse em Libras: essa pesquisa está sendo realizada por José Ishac Brandão El Khouri, orientado pela Profa. Dra. Mônica Veloso, professora da UFG, colaboradora no Programa de Pós-graduação em Letras. É um projeto de dissertação e tem como objetivo descrever as estratégias gramaticais, bem como identificar alguns sinais gramaticais que indicam posse em libras.

\section{- Pesquisa sobre Orações Complexas em Libras: essa} pesquisa será realizada por Cleysson Wender Fernandes Pires, Bolsista de iniciação científica, e será orientado por Carlos Ludwig. Tem por objetivo analisar as orações complexas em libras, principalmente as orações complexas por parataxe, hipotaxe e encaixamento.

- Criação de um Corpus de Narrativas em Libras do Tocantins: Esse projeto será desenvolvido por Roselba Miranda, Jefferson Brandão de Feitosa e Bruno Carneiro. O objetivo desse projeto será coletar narrativas de surdos do Tocantins. O projeto estará vinculado ao Inventário da Libras da Região de Palmas.

\section{CONSIDERAÇÕES FINAIS}

Este artigo intitulado Inventário da libras no Tocantins: constituição e coleta de dados objetivou discutir a proposta de documentação da libras que será desenvolvida no projeto Inventário da Língua Brasileira de Sinais da Região Metropolitana de Palmas - Tocantins. Conforme mencionamos, este projeto está vinculado a um projeto maior, o DOI: http://dx.doi.org/10.20873/uftv7-5794
Inventário Nacional da Língua Brasileira de Sinais, coordenado pela Profa. Dra. Ronice Müller de Quadros, da Universidade Federal de Santa Catarina. A finalidade é criar um corpus da libras representativo do estado do Tocantins.

As línguas de sinais brasileiras são línguas consideradas em risco, apesar de apresentares status de risco distintos. As línguas de sinais nativas possuem o risco eminente de serem extintas, diante de uma provável postura hegemônica frente a uma língua de sinais nacional. A língua de sinais nacional, a libras, é uma língua considerada em risco esquecida, apesar de possuir um certo reconhecimento e prestígio enquanto língua do país. Isso acontece porque os falantes utentes da libras, que dela dependem para o desenvolvimento de todas as funções cognitivas, emotivas e sociais que perpassam pela língua em uso, tem acesso tardio a ela.

Nesse sentido, o Inventário da Libras no Tocantins supre essa necessidade premente de identificação, reconhecimento, valorização e documentação da língua brasileira de sinais, em particular as variantes em uso no estado do Tocantins. Além da documentação da libras no Tocantins, análises com dados do corpus da libras serão desenvolvidas, a fim de oportunizar mais estudos linguísticos da libras não só no estado, mas também no cenário nacional. Estas são ações fundamentais para a implementação de políticas linguísticas, educacionais e de acessibilidade envolvendo a comunidade surda brasileira.

O Inventário da Libras no Tocantins adotará os mesmos procedimentos metodológicos do projeto matriz, com sede na UFSC, que envolve etapas de constituição e a metodologia de coleta, transcrição e análise dos dados específicos. 
Ressaltamos que no estado do Tocantins, a UFT, através do Curso de Letras Libras e do Programa de Pós-Graduação em Letras, ambos no Campus de Porto Nacional, têm contribuído com pesquisas linguísticas sobre a libras e educação de surdos. Uma dessas ações envolve o Inventário da Libras no Tocantins, que conta com grande parte de suas ações coordenadas por professores surdos, a garantir uma perspectiva surda na construção de conhecimento. A UFT hoje possui 13 professores surdos efetivos que, articulados à comunidade surda local, contribuem para a implementação de políticas frente as demandas legais que ora se apresenta no cenário estadual e municipais.

Mais uma vez, conforme ressalta Quadros (2016), a documentação da libras, através do projeto do Inventário, assegura ações de difusão, manutenção e revitalização desta, além de figurar enquanto mantenedora do patrimônio imaterial da diversidade linguística brasileira. $\mathrm{O}$ projeto do Inventário da libras no Tocantins é uma ação nesse sentido.

\section{REFERÊNCIAS}

BRASIL. Lei $\mathrm{N}^{\circ} 10.436$ de 24 de abril de 2002. Dispõe sobre a Língua Brasileira de Sinais - Libras e dá outras providências.

BRASIL. Decreto N 5626 de 22 de dezembro de 2005. Regulamenta a lei $\mathrm{n}^{\circ} 10.436$ de 24 de abril de 2002, que dispõe sobre a Língua Brasileira de Sinais - Libras, e o art. 18 da Lei $\mathrm{n}^{\circ} 10.098$, de 19 de dezembro de 2000.

CARNEIRO, B.G.; NUNES, E.F. Empoderamento da comunidade surda tocantinense. Documentação da Língua Brasileira de Sinais. Anais do Seminário III CIDS Congresso Internacional de Dialetologia e Sociolinguística - variedade, atitudes linguísticas e ensino. Londrina, PR, 2014, p. 198-207.

CARNEIRO, B.G. O corpo na concepção de eventos na língua de sinais brasileira. Antares: Letras e Humanidades, v. 7, n. 14, jul/dez, 2015.

CARNEIRO, B.G. Corpo e classificadores nas línguas de sinais. Revista Sinalizar, v. 1, n. 2, p. 118-129, jul/dez, 2016a.

DOI: http://dx.doi.org/10.20873/uftv7-5794
CARNEIRO, B.G. Ampliação lexical da língua de sinais brasileira: aspectos icônicos. Revista Leitura, v. 1, n. 57, p. 104-119, jan/jun, 2016b.

CARNEIRO, B. G. Emergência de um padrão surdo do português escrito. Revista Porto das Letras. vol. 4, n. 1, p. 119-132, 2018.

COURA, F.A. Resistências e conquistas na educação e no ensino de leitura e escrita de línguas orais para alunos surdos. Interletras, v. 6, n. 4, p. 1-18, 2016.

COURA, F.A. Critical Literacy in English classes: discussions about deaf, blind and deaf-blind people. In: OLIVEIRA, A.L.A.M.; BRAGA, J.C.F. (Orgs.). Inspiring insights from an English teaching scene. Belo Horizonte: Editora da UFMG, 2017, p. 44 - 64.

FELIPE, T.A. O Signo Gestual-Visual e sua Estrutura Frasal na Língua dos Sinais dos Centros Urbanos Brasileiros. Dissertação (Mestrado) Universidade Federal de Pernambuco, Recife, 1988.

FELIPE, T.A. A relação sintático-semântica dos verbos na Língua Brasileira de Sinais (LIBRAS), Tese (Doutorado) - Universidade Federal do Rio de Janeiro, Rio de Janeiro, 1998.

FERREIRA-BRITO, L. Similarities and differences in two brazilian sign languages. Sign Language Studies, vol. 42, spring, p. 45-56, 1984.

FERREIRA, Lucinda. Por uma gramática de línguas de sinais. Rio de Janeiro: Editora Tempo Brasileiro. Reimpressão. 2010.

GERACI, C.; BATTAGLIA, K.; CARDINALETTI, A.; CECCHETTO, C.; DONATI, C.; GIUDICE, S.; MEREGHETTI, E. The LIS Corpus Project: a discussion of sociolinguistic variation in the lexicon. Sign Language Studies, vol. 11, n. 4, sum, p. 5285746, 2011.

KHOURI, J. I. B. E.; CARNEIRO, B. G.; CRUZ, A. Verbos de indicação na libras: possíveis evidências de distanciamento. Porto das Letras, v. 3, n.1, p. 88100, 2017.

LEITE, T.A. A segmentação da língua de sinais brasileira (libras): um estudo linguístico descritivo a partir da conversação espontânea entre surdos. 2008. 280 f. Tese (Doutorado em Estudos Linguísticos e Literários em Inglês) - Faculdade de Filosofia, Letras e Ciências Humanas, Universidade São Paulo, São Paulo, 2008.

LEITE, T. A.; QUADROS, R. M. Línguas de sinais do Brasil: reflexões sobre o seu estatuto de risco e a importância da documentação. In: STUMPF, M.; QUADROS, R. M.; LEITE, T. A. Estudos da 
Língua Brasileira de Sinais II. Florianópolis: Insular, 2014. Cap. 1. p. 15-28.

LREC Proceedings of 3rt. Workshop on the Representation and Processing of Sign Languages: Construction and Exploitation of Sign Language Corpora, Marrocos, 2008. Disponível em < http://www.sign-lang.unihamburg.de//rec2008/main.html >. Acessado em 26 de agosto de 2018.

LUDWIG, C. R.; QUADROS, R. M., Inventário da Língua Brasileira de Sinais da Região de Palmas Tocantins. (Projeto de Pesquisa). Porto Nacional: UFT, 2018.

MAIA, M.I.Z. A importância da história dos surdos para o avanço da educação. Porto das Letras, v. 3, n.1, p. 101-111, 2017.

NASCIMENTO, S. P. F. do. Representações Lexicais da Língua Brasileira de Sinais: Uma Proposta Lexicográfica. Tese de Doutorado Universidade Federal de Brasília, Brasília, 2009.

NONHEBEL, A.; CRASBORN, O.; KOOIJ, E.V.D. LREC Sign language transcription conventions for the ECHO Project: BSL and NGT mouth annotations. Version 2, 20 jan, 2004. Disponível em < file:///Users/macair/Downloads/NonhebelCrasbo rnKooij2004transcriptionmouth\%20(1).pdf>

Acessado em 26 de agosto de 2018.

O'KEEFE, A.; MICHAEL, M. The routledge handbook of corpus linguistics. London: Routledge, 2010.

PAZ, G.G.G; CARNEIRO, B.G.; MIRANDA, R.G. Sinalário de termos científicos em libras e seu uso na escola. Revista Virtual de Cultura Surda e Diversidade, edição n ${ }^{\circ}$ 18, v. Julho, p. 1-16, 2016.

PIZZUTO, E.; PIETRANDREA, P. Open questions and indications for further research. The notation of signed texts: open questions and indications for further research. Sign Language \& Linguistic, v. 2, n.1/2, p. 29-45, 2001.

QUADROS, R. M. de. Phrase Structure of Brazilian Sign Language. Tese de Doutorado. Pontifícia Universidade Católica do Rio Grande do Sul - PUC-RS. Porto Alegre, 1999.
QUADROS, R. M. e KARNOPP, L.B. Língua de sinais brasileira: estudos linguísticos. Porto Alegre: Artmed, 2004.

QUADROS, R.M. Documentação da Língua Brasileira de Sinais. Anais do Seminário Iberoamericano de Diversidade Linguística. GARCIA, M.V. C. (orgs.) Brasília, DF: Iphan, 2016, p. 157-174

QUADROS, R. M.; SILVA, D. S. da S. As comunidades surdas brasileiras. In: ZAMBRANO, R. C.; PEDROSA, C. E. F. Comunidades Surdas na América Latina. Florianópolis: Editora Bookess, 2017, p. $135-152$.

STOKOE, W.C. Sign language structure: an outline of the visual communication systems of the American deaf. Studies in linguistics: ocasional papers, n. 8 , 1960 .

TREVOR, J. Transcription and glossing of sign language texts: examples from Austan. International Journal Sign Linguistics, v. 2, n.1, p. 3-28, 1991.

TREVOR, J. The lexical database of Auslan. Sign language \& Linguistics, v. 3, n.1-2, p. 145-169, 2001.

TREVOR, J.; SCHEMBRI, A. Issues in the creation of a digital archive of a signed language. In: BARWICK, L; THIEBERGER, N. (Eds). Sustainable data from digital fielwork. University of Sydney Press: Sydney, 2006, pp. 7-16.

TREVOR, J.; SCHEMBRI, A. Testing language description through language documentation, archiving and corpus creation: the case of indication verbs in Auslan Archive Corpus. Proceedings of Conference on Language Documentation \& Linguistic Theory. London: SOAS, 2007, pp. 7-16.

XAVIER, A. N. Descrição Fonético-Fonológica dos Sinais da Língua de Sinais Brasileira (Libras). Dissertação de Mestrado - Universidade de São Paulo, São Paulo, 2006.

ZESHAN, Ulrike. Sign Languages. In: DRYER, Mattheus; HASPELMATH, Martin (Eds.). The World Atlas of Language Structures Online. Leipzig: Max Planck Institute for Evolutionary Anthropololy, 2013c. Disponível em: http://wals.info/chapter/s9. Acessado em 19 de junho de 2018. 